\title{
The effect of fabric's structure on the breathability and the drying rate properties
}

\author{
Mohamed Ghaith Chakroun*, Sofien Benltoufa, Faten Fayala \\ LESTE (Laboratoire d'étude des systèmes thermiques et énergétiques), National Engineering School of Monastir, \\ University of Monastir, Tunisia. \\ ${ }^{*}$ Corresponding author E-mail address: medghaithchakroun@gmail.com
}

\section{INFO}

CDAPT, ISSN 2701-939X

Peer reviewed article

2021, Vol. 2, No. 1, pp. 61-69

DOI 10.25367/cdatp.2022.2.p61-69

Received: 14 May 2021

Accepted: 21 June 2021

Available online: 27 June 2020

\begin{abstract}
Many parameters affect sportswear comfort. Therefore, we selected five sportswear fabrics designed for jogging and hiking $T$ shirts to study their structural characteristics and to investigate the influence of these characteristics on the clothing comfort properties. The areal weight, the thickness, the loop length and the course and wales densities were calculated. Investigations were performed on air permeability, water vapor resistance and drying time/rate properties of selected fabrics. We found that an increase in the mass per square meter and in thickness decreases the air permeability and increases the water vapor resistance of knitted fabrics. The air permeability is proportional to the loop length, while the water vapor resistance is inversely proportional to the loop length. Finally we did not find any significant relation between the fabric's structure characteristics and the drying time/rate.
\end{abstract}

\section{Keywords}

Air permeability,

Water vapor permeability,

Clothing comfort,

Drying rate (c) 2021 The authors. Published by CDAPT.

This is an open access article under the CC BY-NC-ND license https://creativecommons.org/licenses/ peer-review under responsibility of the scientific committee of the CDAPT.

(C) 2021 CDAPT. All rights reserved.

\section{Introduction}

The human need of comfort is a way to improve the quality of life. It is fulfilled by providing a satisfactory and pleasant environment, foremost improving clothes, since we are dressed up all the time. The clothing comfort may be defined as a human psychological perception related to clothing ensemble, which is an outcome of the complex linkages between individual sensory stimuli received by brain, evaluation and weighing of all these stimuli to formulate subjective perception of overall comfort based on wear experience [1]. Comfort is a crucial requirement of clothing, which can be categorized into four aspects: physiological comfort, tactile comfort, ergonomic comfort and psychological comfort. Physiological comfort is a very complicated aspect, because it depends on the physical activity of the 
wearer (sleep, rest, walk, run) and the environment surrounding it (cold, warm, humid). Following this change, the physiological responses and the clothing interactions with the human body change too.

During sports activities, several intense physiological mechanisms of heat loss are activated to prevent an excessive rise in body temperature and maintain thermal comfort [2]. The excess heat must first be transported from inside the body to the skin where heat can be lost through heat exchange with the environment. Once metabolic heat is transferred to the skin, there are different ways it is lost to the environment. Heat can be transferred within clothing in the form of conduction, convection, radiation and latent heat transfer by moisture transport. Conduction, convection and radiation are dominated by the temperature difference between skin surface and the environment and are therefore grouped as a dry heat transfer. On the other hand, latent heat transfer is achieved by moisture transmission related to water vapor pressure between the skin surface and the environment [3]. The clothes and the still air entrapped between the skin and the fabric's inner layer form a barrier that influences the heat loss processes of the body. So the garment must have properties that promote the natural phenomena of the human body to avoid body hyperthermia and have a state of discomfort that could pass into a pathological state. Furthermore, the accumulation of liquid sweat on the skin or the fabric's inner surface affects the physiological and tactile comfort of the wearer. Thus, studying and improving the thermal behavior governed by the air permeability and the water vapor resistance property of fabrics serves to enhance the clothing comfort.

The properties must be explained by the structure; many research groups have studied the influence of the fiber's, the yarn's and the fabric's structure on thermal and moisture management properties. Esra and Binnaz [4] investigated the thermal resistance, absorptivity and conductivity, air permeability and moisture management properties of fabrics made of different types of polyester yarns. The results showed that textured polyester yarn knitted fabrics had the highest air permeability values as compared to moisture management polyester with the same yarn count and knit structure. Lower filament number fabrics showed higher thermal resistance values in the same yarn count of fabrics. Moisture management polyester knitted fabrics showed the highest top absorption and one-way transport index value.

Mikučionienè et al. [5] studied the influence of the loop length on air permeability of single jersey knitted fabrics. They found that an increase in the loop length of the knit increases their permeability to air. Similar results were found by Ebru [6] who investigated the influence of the knitting structure on water vapor and air permeability. Results showed that an increase in the loop length increased the permeability to air and an increase in the linear density of yarns decreased the water vapor permeability of the knits.

Figen and Yıldıray [7] used FX3300-III air permeability tester instrument and SDL Atlas MMT Moisture Management Tester to investigate the air permeability and moisture management properties, respectively, of knitted fabrics with different knit type, yarn count and mass. They revealed that air permeability decreased not proportionally to the mass of fabrics, Rib fabrics had higher air permeability values as compared to single jersey fabrics, single jersey and rib fabrics' moisture management properties decreased as the fabrics' mass increased, and wetting time and absorption rate increased as the single jersey fabrics' mass increased.

Esra et al. [8] investigated the effect of fiber cross sectional shape on the thermal properties, water vapor and air permeability. Four type of fiber were used - round, hollow round, trilobal and hollow trilobal - to prepare two types of weaves: plain and twill. They found that the thermal conductivity increased in the fabrics woven with hollow fibers when compared to those woven with solid fibers, contrary to the water vapor and air permeability. The fabrics woven from trilobal fibers had lower thermal conductivity and thermal absorption and higher water vapor and air permeability values than those woven from round fibers.

Sampath et al. [9] made five different fabrics from 150 denier polyester yarns constituting different numbers of filaments. They investigated their wetting, vertical wicking, transverse wicking, and moisture vapor transfer. They concluded that when the filament fineness in the fabric increased, wicking rate and 
wicking height first increased and then decreased, while the wicking rate and wicking height increased with time for all fabrics. In transverse wicking, when the filament fineness increased, the area of water spread increased and correspondingly the time taken to reach saturation point also increased.

In this study, we measured first the mass, loop length, thickness, course and wale density of five knitted fabrics made for sportswear, and then we studied the air permeability, water vapor resistance and drying time/rate as a function of the structure parameters.

\section{Experimental methods}

The specimens were cut at least $10 \mathrm{~cm}$ away from the selvage and creases and folds have been avoided. $24 \mathrm{~h}$ conditioning of the specimens and all experiments were carried out in a standard atmosphere of $(65 \pm 2) \%$ relative humidity and $(20 \pm 2){ }^{\circ} \mathrm{C}$ temperature for testing. The mass per unit area was measured according to the test method EN 12127. The thickness was determined in accordance with the standard ISO 5084-1996 with $0.1 \mathrm{kPa}$ pressure. Course and wale density values per $\mathrm{cm}$ were taken into account for the study in conformity with standard EN 14971:2006 method A. The loop length of 100 needles was measured according to EN 14970:2006. The TEXTEST Air Permeability Tester FX 3300 LABOTESTER III was used for accurate determination of the air permeability with a 100 $\mathrm{kPa}$ pressure difference and $20 \mathrm{~cm}^{2}$ test area according to ISO 9237:1995. The air flow through the test specimen is measured with a variable orifice. The air permeability of the test specimen is determined from the pressure drop across this orifice, and is digitally displayed in the selected unit of measure for direct reading [10]. To measure the water vapor resistance, the PERMETEST Sensora instrument was used in accordance with ISO 11092. The Permetest instrument is also called skin model, which simulates dry and wet human skin in terms of its thermal feeling [11].

The drying time was measured using an internal test method. Initially, the fabric sample's (circular specimen size $\left.100 \mathrm{~cm}^{2}\right)$ mass was measured and recorded. Then, a (20 \pm 2$) \mathrm{mg}$ distilled water drop was placed on the digital scale, immediately the specimen was placed (back side down) gently on the drop, the drop must be at the specimen's center. At this moment the chronometer was launched. The mass was recorded at 2 minutes intervals until the mass has returned to the original fabric sample mass. The time when the mass has returned to the fabric initial mass is defined as the drying time. As shown in Fig. 1, the air can penetrate to the glass box from the top, the right and the left side in the test apparatus. The test is carried out in the normal conditioning atmosphere as mentioned above and without air flow, i.e. the air velocity through the exposed faces must not exceed $0.1 \mathrm{~m} / \mathrm{s}$.

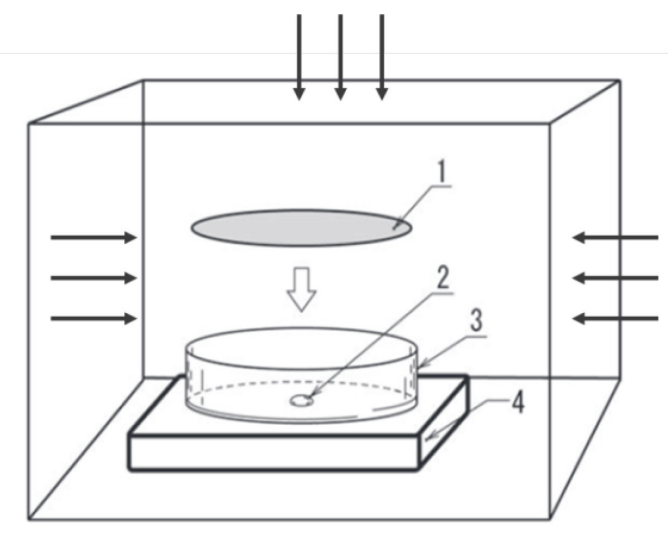

Key :
1) Specimen
2) Drop of distilled water $\longrightarrow$ : Air flow
3) Petri dish
4) Digital scale

Fig. 1 The test apparatus for determining the drying time/rate. 
In this internal test method, it is not mentioned how we calculate the drying rate, which is a key factor in the study of the drying phenomena of fabrics. So we referred to the international standard ISO 17617:2014 for the determination of the drying rate. First, we calculated the percentage of water loss by mass $L_{t}$ according to equation (1).

$\mathrm{L}_{\mathrm{t}}(\%)=\frac{\mathrm{M}_{0}-\mathrm{M}_{\mathrm{t}}}{\mathrm{M}_{\mathrm{D}}} \times 100$,

where:

- $M_{0}$ : mass of the wetted sample at $t=0$.

- $\mathrm{M}_{\mathrm{t}}$ : mass of the wetted sample at $\mathrm{t}$.

$-M_{D}$ : mass of the water drop.

The mass unit used for all mass values in equation (1) is gramm (g).

Then, the regression line of the water mass loss as a function of time is determined and the drying rate is defined according to the ISO 17617 as the slope of this linear curve. For each fabric three test specimens were considered in the measurement of the drying time and rate and their mean value was considered for this investigation.

Figure 2 shows the evolution of water mass loss in time of the V93 fabric. The equation of the regression line is " $y=0.0323 \mathrm{x} / \mathrm{min}+0.0172$ ", consequently the slope is equal to $0.0323 / \mathrm{min}$. The drying rate of V93 is $3.23 \% / \mathrm{min}$.

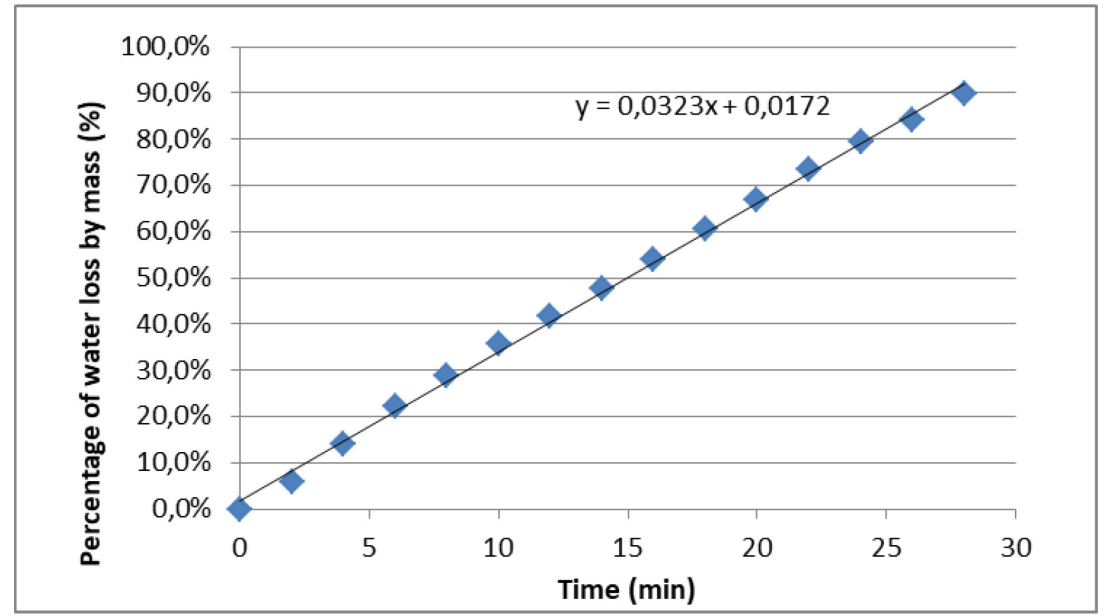

Fig. 2 Evolution of water mass loss as a function of time of V93.

\section{Materials}

Five types of knitted fabrics for sportswear were selected for this study. The knitting, dyeing and finishing were accomplished in VTL group (Société Tunisienne de Vêtement de Travail et de Loisir) in Tunisia. The yarns used in the study made with a natural fiber, wool merino, and man-made fibers with circular cross sectional shape: polyamide (PA) and polyester (PES). Four kinds of man-made yarns were employed: $100 \%$ PES, $100 \%$ PA, PA/PES mixture and PES COC. PES COC is a COCONA $®$ polyester yarn made with polyester fibers that have $37.5^{\circledR}$ technology. They work through permanently integrated active particles that capture and release water vapor and actively react to body heat. The particles use the body's infrared energy to accelerate the movement of vapor and evaporation of liquid.

All fabrics were made on a single jersey machine, gauge E 28. Details of the knitted hoses made are given in Table 1. 
Table 1. Details of the knit hoses.

\begin{tabular}{lllll}
\hline Code & Pattern & Composition & $\begin{array}{l}\text { Fiber fraction } \\
(\mathbf{\%})\end{array}$ & $\begin{array}{l}\text { Linear density } \\
\text { (dtex) }\end{array}$ \\
\hline V06 & Jersey crepe & PES & 43 & $83 / 72$ \\
& & PES COC & 43 & $83 / 42$ \\
& & Elasthane & 14 & 22 \\
V93 & & & $83 / 72$ \\
& Jersey crepe & PES & 50 & $83 / 42$ \\
V05 & PES COC & 50 & $83 / 72$ \\
& & & & $83 / 42$ \\
V16 & Jersey crepe & PES & 50 & 138 \\
& & PES COC & 50 & $55 / 24$ \\
V19 & Woneycomb & PES merino & 67 & $77 / 82$ \\
& & & 33 & $22 / 7$ \\
\hline
\end{tabular}

As presented in Table 1, Fabrics V06, V93 and V05 have the same pattern and they are made with the same yarns except in fabric V06 which is plated with an elasthane yarn. The difference between V93 and V05 is the loop length. All fabrics were washed and dyed on industrial scale. Finishing treatments and heat settings were done on a stenter machine which is a specialist oven used in the textile industry for drying and heat treating fabric after wet processing. V93, V05, V16 and V19 underwent a hydrophilic treatment using ULTRPHIL $®$ which is a moisture management agent, padded at a speed of $20 \mathrm{~m} / \mathrm{min}$ with a liquor pick of $50 \%$, bath temperature of approximately $20^{\circ} \mathrm{C}$ and a drying temperature of $120{ }^{\circ} \mathrm{C}$. Structure characteristics of the finished fabrics are presented in Table 2.

Table 2. Structure characteristics of the finished fabrics. CV = coefficient of variation.

\begin{tabular}{|c|c|c|c|c|c|c|c|c|c|c|}
\hline Code & $\begin{array}{l}\text { Areal } \\
\text { mass } \\
\left(\mathrm{g} / \mathrm{m}^{2}\right)\end{array}$ & $\begin{array}{l}\text { CV } \\
\text { (\%) }\end{array}$ & $\begin{array}{l}\text { Thickness } \\
(\mathrm{mm})\end{array}$ & $\begin{array}{l}\text { CV } \\
\text { (\%) }\end{array}$ & $\begin{array}{l}\text { Course } \\
\text { density } \\
\text { (course/cm) }\end{array}$ & $\begin{array}{l}\text { CV } \\
(\%)\end{array}$ & $\begin{array}{l}\text { Wale } \\
\text { density } \\
\text { (wale/cm) }\end{array}$ & $\begin{array}{l}\text { CV } \\
(\%)\end{array}$ & $\begin{array}{l}\text { Loop length } \\
\text { (cm) }\end{array}$ & $\begin{array}{l}\text { CV } \\
\text { (\%) }\end{array}$ \\
\hline V06 & 133.08 & 1.2 & 0.670 & 2.1 & 16.0 & 0 & 25.0 & 0 & 21.6 & 2.9 \\
\hline V93 & 66.99 & 1.6 & 0.564 & 1.6 & 14.8 & 4.4 & 15.2 & 2.9 & 25.0 & 1.2 \\
\hline V05 & 108.56 & 2.9 & 0.572 & 2.9 & 17.5 & 2.9 & 23.8 & 4.2 & 17.1 & 2.0 \\
\hline \multirow[t]{2}{*}{ V16 } & 120.96 & 1.1 & 0.924 & 2.6 & 18.0 & 0 & 32.0 & 0 & Wool 23 & 3.3 \\
\hline & & & & & & & & & PES 17.2 & 2.5 \\
\hline \multirow[t]{2}{*}{ V19 } & 89.89 & 0.9 & 0.524 & 1.7 & 17.3 & 0 & 22.8 & 0 & PA/PES 21.3 & 1.9 \\
\hline & & & & & & & & & 13.6 & 1.1 \\
\hline
\end{tabular}

For a better understanding of the finished fabric's structure and design, we took microscopic images of the front and back side of each one, as illustrated in Figure 3. The magnification scale of all fabrics images is $x 51$ except for V16 where we put a microscopic image less magnified then the other fabrics $(x 32)$ to visualize clearly the honeycomb unit structure which is larger than the other samples. 
V16
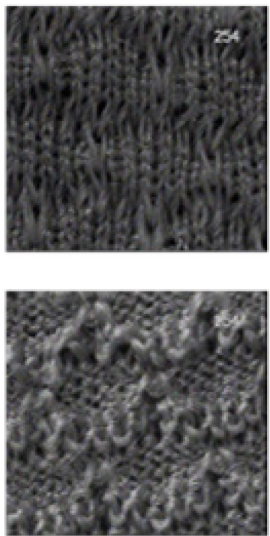

$\times 32$
V06
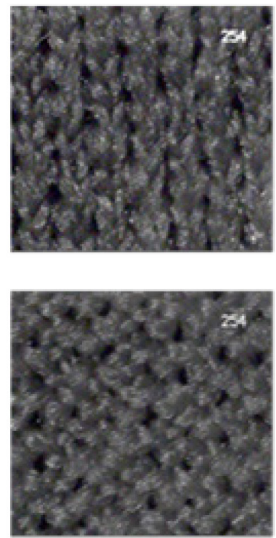

$\times 51$
V05
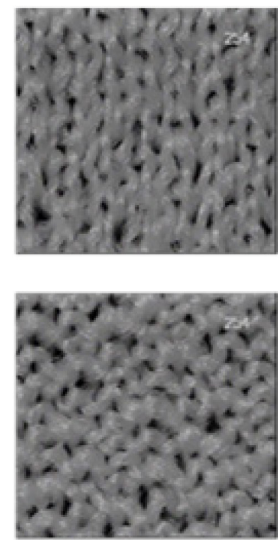

$\times 51$
V93
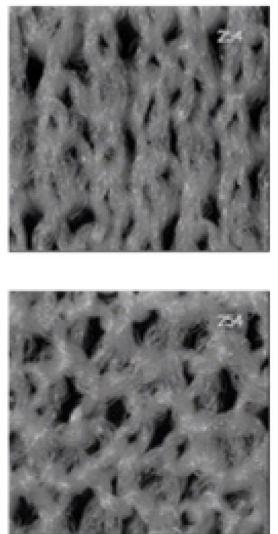

$\times 51$
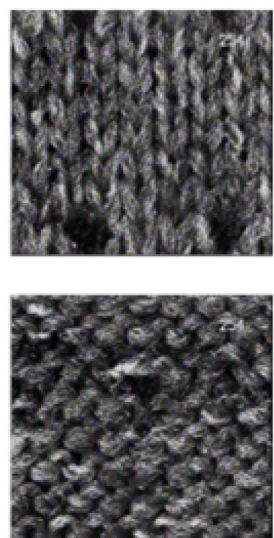

$\times 51$

Fig. 3 Microscopic images of the two sides of the finished fabrics.

\section{Results and discussion}

We plotted the error bars in all the charts of this section, to indicate the uncertainty of the reported measurements. Also the coefficient of variation (CV) has been found beneath $4 \%$ in the air permeability test, beneath $5 \%$ in the water vapor resistance measurements and beneath $6 \%$ in the drying time and the drying rate determination.

\subsection{The influence of fabric's structure on the air permeability}

Air permeability is the rate of air flow passing perpendicularly through a known area under a prescribed air pressure differential between two surfaces of a material [12]. Air permeability values of fabrics used in the experiments are compared in Figure 4.

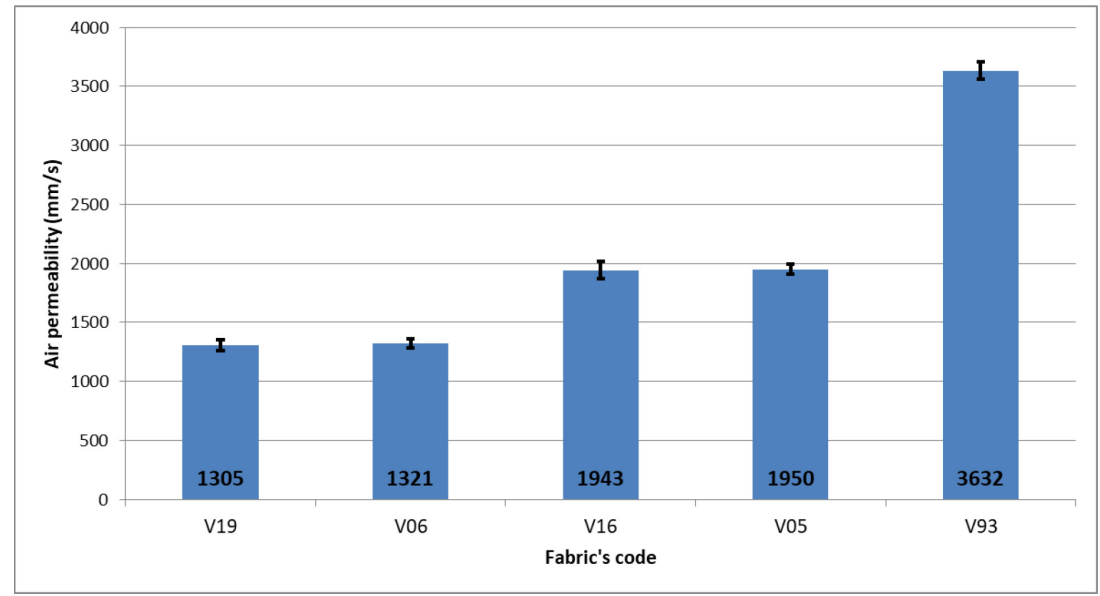

Fig. 4 Air permeability of used fabrics.

The highest air permeability value (V93) was noticed in the highest loop length and lowest course and wale densities, and consequently the lowest mass per unit area. The lowest air permeability values were found in fabric V19; this may be explained by the reduced number of macro pores through which most of the airflow permeates.

When comparing V093, V05 and V06, the heaviest and thickest fabric V06 shows the lowest air permeability value. This is explained by the presence of Lycra yarn, which made the structure tighter and reduces the spaces within yarns, hence decreasing the airflow passing through the fabric. So an 
increase in the mass per unit area and the thickness leads to a decrease in the air permeability of fabrics.

When comparing V093 and V05, we found that air permeability increased significantly when the loop length increased. The air permeability is proportional to the loop length and inversely proportional to fabric's mass per unit area and thickness.

\subsection{The influence of fabric's structure on the water vapor resistance}

Water vapor resistance is the fabric's resistance to transport the moisture (in vapor form) away from the skin. Fabrics have to evacuate this vapor before it becomes liquid, avoiding the fabric to get wet and reducing the uncomfortable sensation of the wearer [13]. According to Figure 5, the highest water vapor resistance was seen in V16 which is the thickest fabric and has the highest stitch density. The lowest water vapor resistance is visible in V93 which has the highest air permeability value, which is explained by the high porosity of this fabric that allows both the air flow and the water vapor to permeate through the fabric layer effectively.

Comparison of jersey crepe knitted fabrics V93, V05 and V06, the highest water vapor resistance value was seen in V06. Similar to the air permeability, the heaviest and thickest fabric has the highest water vapor resistance. So, heavy and thick fabrics do not promote heat loss by evaporation. Accordingly, the water vapor resistance is proportional to the fabric's square mass and thickness. From comparing V93 and V05 we can say that an increase in loop length decreases the water vapor resistance of fabrics.

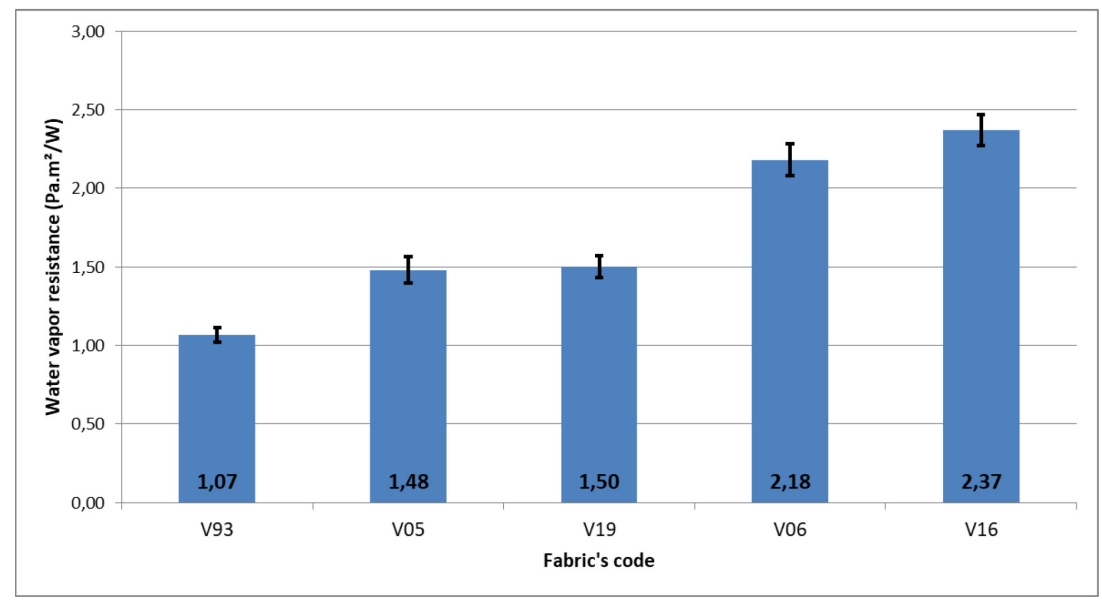

Fig. 5 Water vapor resistance of used fabrics.

\subsection{The influence of fabric's structure on the drying rate/time}

Drying rate is defined as the required time to dry a known mass of moisture from a textile fabric. It is expressed in drying percent per unit time. Another parameter related to drying is the drying time defined as the time for which $100 \%$ of applied water loss occurs [14]. The drying rate and time of all fabrics are compared in Figure 6. It is evident that the fabric having the highest drying rate is the fastest one to dry. The lowest drying rate was seen in V16 which contains the wool yarn. The absorption of water by the wool fibers makes the loss of water by evaporation more difficult than the hydrophobic man-made fibers where the water remains on the fiber's surface.

The highest drying rate among jersey crepe fabrics was seen in V05 which have the lowest loop length. Nevertheless, the drying rate cannot be explained by the loop length, since a great loop length difference between V05 $(17.1 \mathrm{~cm})$ and V93 $(25 \mathrm{~cm})$ shows an approximately same drying rate. Thus, there is no significant influence of the loop length on the drying rate. 

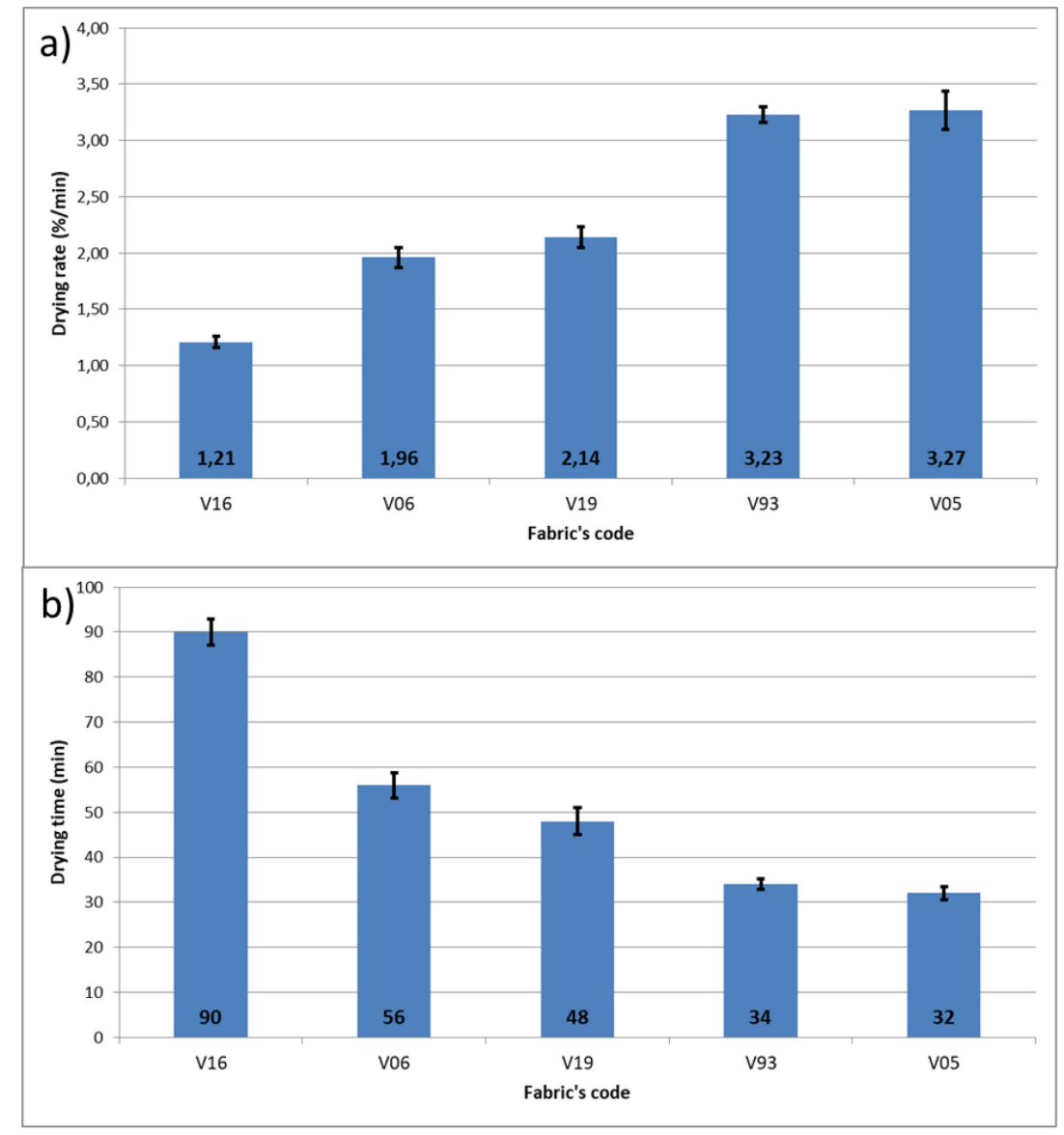

Fig. 6 (a) Drying rate; (b) drying time of fabrics used in the experiments.

\section{Conclusion}

The main conclusions drawn from this work are: First, air permeability is low in tight fabrics. Second, an increase in the mass per unit area and the thickness leads to a decrease in the air permeability and an increase in the water vapor resistance of knitted fabrics. Third, the air permeability is proportional to the loop length. Fourth, the water vapor resistance is inversely proportional to the loop length. Fifth, the presence of a hydrophilic fiber affects the water vapor resistance and the drying behavior of fabrics. Sixth, there is not a significant relation found in this investigation of the fabric's structure characteristics on the drying behavior of these fabrics.

Breathability, moisture vapor transmission and fast drying are crucial in determining the comfort in high activity and sportswear clothes. Therefore, the most suitable fabric among the five knitted ones investigated is V93 and in second place we found V05. On the other hand, V06 and V16 are the two fabrics which behaved worst in maintaining a comfort sensation during activities. V19 can be improved by increasing the pore volume by increasing the loop length, for example.

There must be a further investigation of the fiber's and yarn's composition and structure properties for a better understanding of the factors that affects the drying rate of textiles, and likewise, knowing the wetting and wicking behavior of textile structure.

\section{Acknowledgements}

This project is carried out under the MOBIDOC scheme, funded by The Ministry of Higher Education and Scientific Research through the PromEssE project and managed by the ANPR (Agence Nationale de la Promotion de la Recherche Scientifique). 


\section{References}

[1] Apurba Das and Ramsamy Alagirusamy. 2010. Science in Clothing Comfort, Vol. 2: Psychology and Comfort, Woodhead Publishing India Pvt. Ltd.

[2] Daniel Wendt, Luc van Loon and Wouter van Marken Lichtenbelt. Thermoregulation during exercise in the heat strategies for maintaining health and performance. Sports Med. 2007, 37, 669-682.

[3] Dinesh Bhatia and Urvashi Malhotra. 2016. Thermophysiological wear comfort of clothing: an overview. J. Textile Sci. Eng. 2016, 6, 1000250. DOI: https://doi.org/10.4172/2165-8064.1000250.

[4] Esra Taştan Özkan and Binnaz Meriç Kaplangiray. Investigating thermophysiological comfort properties of polyester knitted fabrics. J. Textile Eng. Fashion Technol. 2019, 5, 50-56.

[5] Daiva Mikučionienè, Laima Milašiūtè, Rimvydas Milašius. Influence of knits structure on flammability and comfortability. AUTEX Res. J. 2014, 14, 226-232. DOI: https://doi.org/10.2478/aut-2014-0022.

[6] Ebru Çoruh. Optimization of comfort properties of single jersey knitted fabrics. FIBRES \& TEXTILES in Eastern Europe 2015, 23, 66-72. DOI: https://doi.org/10.5604/12303666.1152728.

[7] Figen Selli, Yıldıray Turhan. 2017. Investigation of air permeability and moisture management properties of the commercial single jersey and rib knitted fabrics. Tekstil ve Konfeksiyon 2017, 27, 27-31.

[8] Esra Karaca, Nalan Kahraman, Sunay Omeroglu and Behcet Becerir. Effects of fiber cross sectional shape and weave pattern on thermal comfort properties of polyester woven fabrics. FIBRES \& TEXTILES in Eastern Europe 2012, 20, 67-72.

[9] M. B. Sampath, Senthilkumar Mani and Govindan Nalankilli. Effect of filament fineness on comfort characteristics of moisture management finished polyester knitted fabrics. J. Ind. Text. 2011, 41, 160-173. DOI: https://doi.org/10.1177/1528083711400774.

[10] Air Permeability Tester FX 3300 LABOTESTER III; ARTEC TESTNOLOGY manual.

[11] Lubos Hes. Non-destructive determination of comfort parameters during marketing of functional garments and clothing. Indian Journal of Fibre \& Textile Research 2008, 33, 239-245.

[12] Banu Özgen and Sevda Altaş. The investigation of thermal comfort, moisture management and handle properties of knitted fabrics made of various fibres. Tekstil ve Konfeksiyon 2014, 24, 272-278.

[13] Amel Boughattas, Sofien Benltoufa and Faten Fayala. Moisture management properties of double face denim fabrics. International Journal of Applied Research on Textile 2019, Special Issue Cirat-8, 38-43.

[14] ISO 17617:2014 Textiles — Determination of moisture drying rate. 